\title{
Potential Implication of Paxillin in Cancer Establishment Within the Bone Environment
}

\author{
ANNA D. SOBKOWICZ, ANDREW J. SANDERS, MALCOLM D. MASON and WEN G. JIANG \\ Cardiff China Medical Research Collaborative (CCMRC), \\ Cardiff University School of Medicine, Cardiff, U.K.
}

\begin{abstract}
Background: Bone metastases are a common feature of advanced prostatic malignancies. They are characterised by a unique prevalence of osteoblastic phenotype and a poor prognosis. Paxillin is a 68-kDa signal transduction adaptor and scaffold protein that contains motifs involved in the mediation of protein-protein interactions. The state of paxillin phosphorylation is central to determining a cell's ability to adhere, detach and migrate and hence has been linked to processes such as wound repair and tumour metastasis. The current study explored the impact of paxillin suppression on prostate and breast cancer cell function and their responsiveness to hepatocyte growth factor (HGF) and bone matrix extract (BME) in order to assess its potential to influence bone colonization and homing. Materials and Methods: Hammerhead ribozyme transgenes were used to knockdown the expression of paxillin in breast and prostate cancer cell lines. The impact on the cell growth, migration, adhesion and invasion was assessed using in vitro functional assays. In order to explore potential mechanisms, focal adhesion kinase (FAK) inhibitor was also used. Results: Knockdown of paxillin expression was observed in all tested cell lines following transfection with the ribozyme transgene. The knockdown of paxillin increased proliferation and invasiveness of LNCaP cells, with no effect on their attachment abilities. The opposite, however, is true for PC-3 cells where, following knockdown, cellular attachment was significantly reduced, while no significant changes in growth and invasiveness were detected. In the MDA-MB-231 breast cancer knockdown model, cells had little difference in proliferative rates and generally increased attachment and reduced invasive abilities. Treatments with $H G F$ and BME had differential effects on targeted cells when compared to controls. Conclusion: These data suggest that
\end{abstract}

Correspondence to: Professor Wen G. Jiang, Cardiff China Medical Research Collaborative (CCMRC), Cardiff University School of Medicine, Henry Wellcome Building, Heath Park, Cardiff, CF14 4XN, U.K. Tel: +44 2920687065, e-mail: jiangw@cf.ac.uk

Key Words: Paxillin, bone, metastasis, prostate cancer, breast cancer. paxillin appears to influence major cell functions in a diverse range of prostate and breast cancer models. The responsiveness of cells to environmental factors such as HGF or BME may be influenced by paxillin status, although this seems to be dependent on cell type.

Prostate cancer remains an ongoing scientific and clinical challenge. Despite the availability of prostate-specific antigen testing, a number of patients newly diagnosed with prostate cancer still present with metastases (1). Half of all patients with metastatic prostate cancer die from the disease within 30-35 months (2) as treatment plans still do not totally prevent the formation of new bone metastases, morbidity or disease progression $(3,4)$. The precise reason why prostate cancer is particularly predisposed to forming bone metastases is as yet unknown. However, it is thought that certain important bone matrix proteins, including vibronectin, bone sialoprotein and collagen type I are facilitated by a number of tethering proteins, such as paxillin, and by reduced blood flow rates which allow prostate cancer cells to adhere, colonise and invade into sites in the long bones $(5,6)$. The inconsistency of metastatic cancer is undoubtedly influenced by the molecular and cellular characteristics of both tumour cells and the tissue which they invade. Since the discovery of hepatocyte growth factor (HGF) several decades ago and the mitogenic, morphogenic, motogenic, angiogenic and cellcycle links that have been described since, HGF and its receptor tyrosine-protein kinase Met (cMET) remain at the forefront of prognostic and therapeutic research (7-9).

The adhesion of cells to the surrounding extracellular matrix (ECM) and their stimulation by growth factors, such as HGF, provide environmental signals critical to controlling a cell's decision to survive, proliferate, differentiate or migrate. Defects in signalling pathways associated with these external signals can lead to developmental abnormalities, degeneration, cell transformation and metastasis (10). Focal adhesions are large, dynamic protein complexes through which the cell cytoskeleton connects to the ECM. They contain a large number of different proteins including focal adhesion kinase (FAK), paxillin, vinculin and integrin alpha-v beta-3, as well as GTPases, and act 
Table I. Sequences and primers used in the current study.

\begin{tabular}{llll}
\hline Target & Gene name & Forward & Reverse \\
\hline$P X N($ PCR $)$ & Paxillin & ACAGTCGCCAAAGGAGTC & TGGTAGTGCACCTCACAGTA \\
GAPDH $(\mathrm{PCR})$ & Glyceraldehyde-3-phosphate dehydrogenase & GGCTGCTTTAACTCTGGTA & GACTGTGGTCATGAGTCCTT \\
$M E T(\mathrm{PCR})$ & MET proto-oncogene, receptor tyrosine kinase & ACTGAACCTGACCGTACA & ATCGAATGCAATGGATGA \\
& & GAGCCAAAGTCCTTCAT & \\
$P X N(\mathrm{qPCR})$ & Paxillin & CAATCCTTGACCCCTTAGA & ACTGAACCTGACCGTACA \\
& & & TTGGAGACACTG \\
GAPDH (qPCR) & Glyceraldehyde-3-phosphate dehydrogenase & CTGAGTACGTCGTGGAGTC & ACTGACCTGACCGTACA \\
& & & CAGAGATGATGACCCTTTTG \\
\hline
\end{tabular}

ACTGAACCTGACCGTACA represents $\mathrm{Z}$ sequence.

to regulate cell adhesion and migration. Paxillin is a signal transduction, multi-domain adaptor protein found at the interface between the plasma membrane and the actin cytoskeleton. It provides a platform for the integration and processing of adhesion- and growth factor-related signals in response to a rapid response to environmental change in ECM (11). Alterations in focal adhesion turnover or component proteins have links to cancer progression and, amongst others, paxillin and FAK have been highlighted as key molecules in this process and have been subject to intense scientific investigation. Overexpression of paxillin has been reported in a number of different human cancer types including oesophageal $(12,13)$, colorectal (14) and lung (15), where paxillin expression is frequently associated with advanced disease and poorer patient outcomes. Another study in breast cancer has suggested that paxillin levels correlate with ERBB2 receptor tyrosine kinase 2 (HER2) amplification and may also influence responsiveness of tumours to chemotherapy, although this appeared to depend on the HER2 status of the tumours (16). Changes in paxillin and FAK expression, phosphorylation or localisation are often associated with enhanced migratory potential and may also represent a means of resistance to cancer therapies (17-20).

Thereby, paxillin provides a platform for the integration and processing of integrin and growth factor-related signals. Given its involvement in a variety of cellular processes, including motility, adhesion and cytoskeletal functions, as well as in recognition and signalling responses to the ECM, we deemed paxillin to be an interesting candidate to study in relation to cancer metastasis and, in particular, in relation to its potential contribution to the very specific homing of cancer cells to the bone environment.

\section{Materials and Methods}

Cell lines and culture conditions. The prostate cancer cell lines PC3 (established from a bone metastasis, osteolytic in nature) and LNCaP (established from lymph node metastasis, possessing a mixed osteolytic and osteoblastic phenotype), and breast cancer cell line MDA-MB-231 (primarily forming osteolytic bone metastasis) were purchased from the American Type Culture Collection (Rockville, MD, USA). Wild-type PC-3 and MDA-MB-231 cell lines were maintained in Dulbecco's modified Eagle's medium (DMEM) supplemented with $10 \%$ foetal calf serum (FCS), penicillin, streptomycin and amphotericin B (Sigma, Poole, Dorset, UK). The wild-type LNCaP cell line was maintained in RPMI-1640 medium supplemented with $10 \%$ FCS, penicillin, streptomycin and amphotericin B (Sigma). Cells transfected with control pEF6 vector (Life Technologies, Paisley, UK) or pEF6 vector containing paxillin ribozyme transgenes were selected in DMEM or RPMI-1640 medium, supplemented with $5 \mu \mathrm{g} / \mathrm{ml}$ blasticidin and subsequently maintained in maintenance medium containing $0.5 \mu \mathrm{g} / \mathrm{ml}$ blasticidin. All cells were grown under standard conditions at $37^{\circ} \mathrm{C}$ and in a humidified atmosphere of $5 \% \mathrm{CO}_{2}$.

Reagents. HGF was a kind gift from Dr T. Nakamura (Osaka University Medical School, Osaka, Japan) and was used in the current study at a concentration of $40 \mathrm{ng} / \mathrm{ml}$. An extract obtained from ground femoral heads termed bone matrix extract (BME) was previously prepared and described by our group (21) and was used in the current study. A small-molecule FAK inhibitor PF 573228 (Sigma) was used on control and knockdown established cancer cell lines to explore potential interactions with the FAK signalling pathway.

Construction of hammerhead ribozyme transgenes targeting human paxillin transcript and generation of paxillin knockdown cells. Targeting of paxillin was accomplished using hammerhead ribozyme transgenes as described previously (22, 23). Briefly, hammerhead ribozymes specific for human paxillin transcript were synthesised using touch-down polymerase chain reaction (PCR) and cloned into pEF6/V5-His-TOPO expression plasmid according to the manufacturer's protocol (Life Technologies). Subsequently, plasmids were amplified in Escherichia coli, extracted and purified before being transfected using electroporation (Easyject, Flowgene, Surrey, UK), into wild type PC-3, LNCaP and MDA-MB-231 cells. Cells underwent a selective period before being transferred into maintenance medium for general maintenance. Reverse transcription polymerase chain reaction (RT-PCR) was used to confirm paxillin knockdown in cells transfected with ribozyme transgene plasmids. Verified knockdown cell lines were termed PC-3 PAXILLIN KD, LNCaPPAXILLIN KD and MDA-MB-231PAXILLIN KD and were subsequently used in the in vitro studies. Control cell lines 
transfected with an empty pEF6 vector were termed PC-3pEF6 LNCaPpEF6 and MDA-MB-231pEF6.

RNA extraction and RT-PCR. RNA extraction from cultures established in T25 tissue culture flasks or multi-well plates was carried out using TRI Reagent in accordance with the supplied protocol (Sigma) and the products were quantified using a spectrophotometer (Wolf Laboratories, York, UK). Samples were standardised to $500 \mathrm{ng}$ and used as a template to generate cDNA using an iScript cDNA synthesis kit (BioRad, Hemel-Hempstead, UK). Following cDNA synthesis, sample quality and uniformity was checked, by simultaneous amplification of the house-keeping gene glyceraldehyde-3-phosphate dehydrogenase $(G A P D H)$. PCR was undertaken in a T-Cy Thermocycler (Creacon Technologies Ltd., CD Emmen, the Netherlands) and performed using REDTaq ${ }^{\circledR}$ ReadyMix $^{\mathrm{TM}}$ PCR Reaction Mix (Sigma) under the following conditions: $5 \mathrm{~min}$ at $95^{\circ} \mathrm{C}, 30$ or 32 cycles $(G A P D H$ and paxillin, respectively) of $30 \mathrm{~s}$ at $94^{\circ} \mathrm{C}, 30 \mathrm{~s}$ at $56^{\circ} \mathrm{C}, 30 \mathrm{~s}$ at $72^{\circ} \mathrm{C}$, and finally $72^{\circ} \mathrm{C}$ for 10 min final extension. Full primer details shown in Table I. PCR products were then separated on a $0.8 \%$ agarose gel, stained with SYBR safe (Life Technologies), visualised and images captured under blue light using an UGenius3 gel doc system (Geneflow, Lichfield, Staffordshire, UK).

Quantitative analysis of gene transcript expression ( $q P C R)$. The level of the GAPDH and paxillin transcripts in control and transfected cell lines was determined using real-time quantitative PCR, based on the previously reported (24) Ampliflor ${ }^{\mathrm{TM}}$ system technology. Briefly, the iCycler IQ ${ }^{\mathrm{TM}}$ system (Bio-Rad) was used to detect and quantify transcript expression in each sample. Pairs of primers (Table I) were designed using Beacon Designer ${ }^{\mathrm{TM}}$ software (Premier Biosoft International, Palo Alto, CA, USA). The Ampliflor system was used together with iQ supermix (Bio-Rad) 10 pmol specific forward primer, 1 pmol reverse primer which has $\mathrm{Z}$ sequence (Table I), 10 pmol of Uniprimer probe (Intergen Inc., New York, NY, USA), and cDNA under the following reaction conditions: 15 -min initial $95^{\circ} \mathrm{C}$ period followed by 60 cycles of $95^{\circ} \mathrm{C}$ for $15 \mathrm{~s}, 55^{\circ} \mathrm{C}$ for $40 \mathrm{~s}$ and $72^{\circ} \mathrm{C}$ for $20 \mathrm{~s}$. Transcript copy number was calculated based on an internal standard simultaneously amplified with the samples. Samples were normalised against GAPDH expression.

In vitro cell growth assay. The assay was based on a previously reported method (25). Cells were plated into 96-well plates (Greiner Laboratories, Stonehouse, Gloucester, UK) at $2.0 \times 10^{3}$ cells/well in their respective medium followed by an incubation period of 1, 3 and 5 days. On each of those days cells were fixed in $4 \%$ formaldehyde [ $\mathrm{v} / \mathrm{v}$ in balanced saline solution (BSS)] and stained with $0.5 \%$ crystal violet $(\mathrm{w} / \mathrm{v})$. Following drying, stained cells were treated with $10 \%(\mathrm{v} / \mathrm{v})$ acetic acid and the absorbance of each individual well was determined at a wavelength of $540 \mathrm{~nm}$ using an ELx800 spectrophotometer (Bio-Tek, Swindon, UK). The measured absorbance value was proportional to the number of cells in each well.

In vitro cell-matrix adhesion assay. The assay was based on a previously reported method (25). Adhesion assays were conducted using 96-well plates pre-coated with $5 \mu \mathrm{g}$ of Matrigel Matrix Basement Membrane (BD Biosciences, Oxford, UK) in $100 \mu \mathrm{l}$ serum-free medium per well and rehydrated prior to use. A total of $4.5 \times 10^{4}$ cells (transfected and controls) were seeded onto Matrigel and incubated for $45 \mathrm{~min}$ at $37^{\circ} \mathrm{C}$. Following incubation, non-adhered cells were removed through multiple washes with BSS and adherent cells were subsequently fixed with $4 \%$ formaldehyde (v/v), stained with $0.5 \%$ crystal violet (w/v) and washed again. Randomly selected fields per well were photographed under a microscope $(\times 200$ magnification $)$ and the number of adhered cells quantified.

In vitro Matrigel invasion assay. Invasion assays were carried out using a method previously described (18). Transwell chambers, equipped with a $6.5 \mathrm{~mm}$-diameter polycarbonate filter insert $(8-\mu \mathrm{m}$ pore size; Griener Bio-One, Gloucester, UK) were pre-coated with $50 \mu \mathrm{g}$ of Matrigel Matrix Basement Membrane and rehydrated briefly before seeding the cells at a density of $2.0 \times 10^{4}$ cells/well. Cells were incubated and allowed to invade for 3 days. Cells that invaded through the basement membrane to the underside of the inserts were fixed with $4 \%$ formaldehyde (v/v in BSS) and stained with $0.5 \%(\mathrm{w} / \mathrm{v})$ crystal violet and washed. For analysis, randomly selected fields per insert were photographed under a microscope ( $\times 200$ magnification) and counted to determine the invasive potential.

In vitro cell migration/wounding assay. The migratory properties of cells were assessed to determine the impact of paxillin knockdown in the prostate and breast cancer cells. This technique has been described in a previous study (26). The cells were seeded onto a 24well plate at a density of $6.5 \times 10^{5}$ cells/well and allowed to reach confluence overnight. The monolayer of cells was then scratched with a pointed plastic pipette tip to create a wound. After the addition of individual HGF, BME, FAK inhibitor or combined HGF and BME treatments, motility of the cells was monitored at $30 \mathrm{~min}$ intervals for $120 \mathrm{~min}$ using an inverted microscope and GXcapture software (GT Vision Ltd., Stansfield, Suffolk, UK).

Wound closure/cell migration was evaluated by calculating the distance between the two wound fronts at several consistent points over all the time intervals and comparison to initial wound size at the respective time zero measurement using ImageJ (Research Services Branch: https://imagj.nih.gov).

Statistical analysis. Data were analyzed using SigmaPlot 11 software. Comparisons between control groups and respective knockdowns or individual treatments were made using Student's $t$ test or Mann-Whitney $U$-tests depending on data normality. Data comparing treatment groups over time were analysed using a two way ANOVA test. Data were considered to be statistically significant at $p \leq 0.05$.

\section{Results}

Expression profiling of cell lines. All prostate (PC-3, DU145, LNCaP, CAHPV10, MDA-PCa-2b and PZHPV7) and breast (MDA-MB-231, MCF-7 and ZR-751) cell lines available within our laboratories were screened for paxillin and $c M E T$ transcript expression in addition to the GAPDH housekeeping gene (Figure 1A). Paxillin and $c M E T$ expression was noted in all tested cell lines and strong paxillin expression was observed in the PC-3, LNCaP and MDA-MB-231 cell lines. 
A

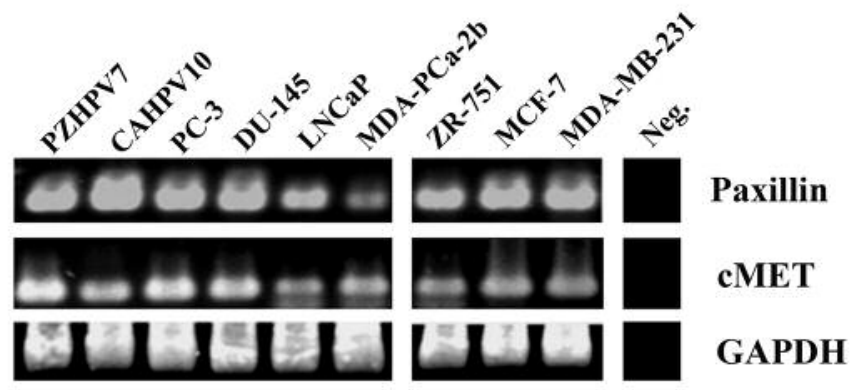

B

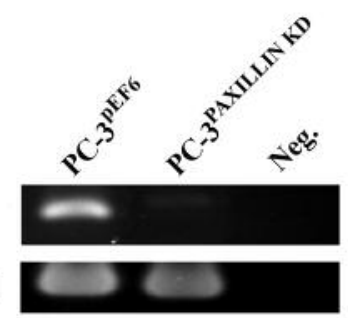

E

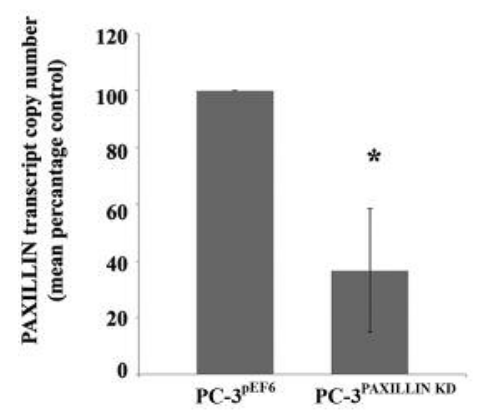

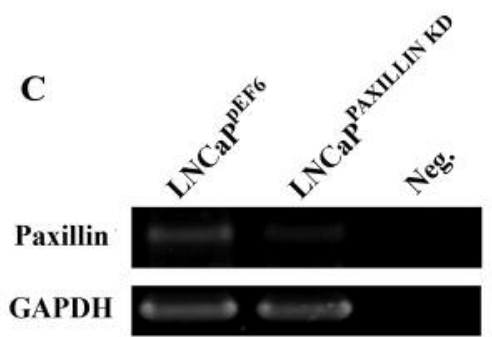

F

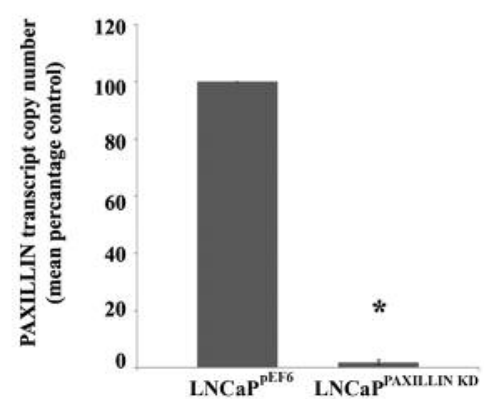

D

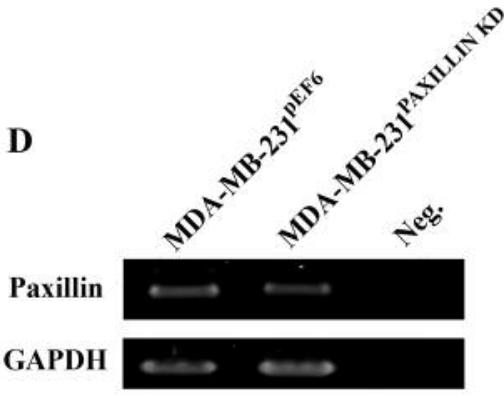

G

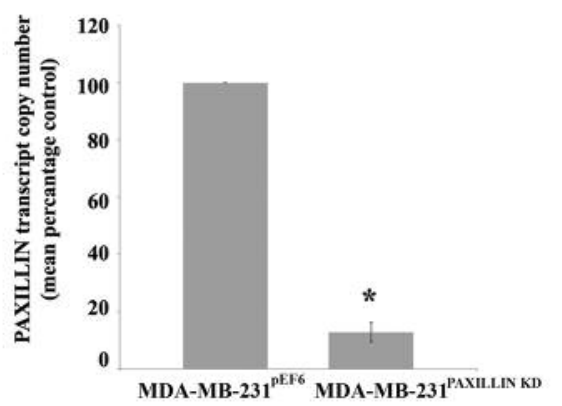

Figure 1. A: Reverse transcription-polymerase chain reaction (RT-PCR) transcript expression profile of paxillin and tyrosine-protein kinase MET (cMET) in a range of prostate and breast cancer cell lines. Positive expression was seen throughout the cell lines, glyceraldehyde-3-phosphate dehydrogenase (GAPDH) was included as a housekeeping gene. RT-PCR confirmed paxillin transcript knockdown (KD) in PC-3 (B), LNCaP (C) and $M D A-M B-231(D)$ cell lines in comparison to the respective controls. Quantitative PCR was also undertaken to confirm paxillin knockdown in $P C-3(E), L N C a P(F)$ and MDA-MB-231 (G) cell lines demonstrating significant levels of knockdown in comparison to respective pEF6 controls. Representative RT-PCR data are shown, qPCR data were normalised against GAPDH and represent the mean percentage of control values \pm SEM of three independent replicates. *Significantly different at $p \leq 0.05$.

Verification of paxillin knockdown in PC-3, LNCaP and $M D A-M B-231$ cells. Given the expression profiles, PC-3, LNCaP and MDA-MB-231 cells were transfected with the paxillin ribozyme transgene. RT-PCR analysis indicated that paxillin transcript expression was successfully knocked down in PC-3, LNCaP and MDA-MB-231 cell lines (Figure $1 \mathrm{~B}, \mathrm{C}$ and $\mathrm{D}$, respectively) in comparison to the expression levels seen in their respective pEF6 plasmid control cell lines (PC-3 ${ }^{\text {pEF6 }}$ LNCaP-3 ${ }^{\text {pEF6 }}$ and MDA-MB-231 ${ }^{\text {pEF6 }}$ ). Quantitative PCR experiments confirmed a significant reduction in expression of paxillin transcript, following normalisation against GAPDH levels, in cells containing the ribozyme transgene $\left(\mathrm{PC}-3^{\text {PAXILLIN KD }}, \mathrm{LNCaP}^{\text {PAXILLIN KD }}\right.$

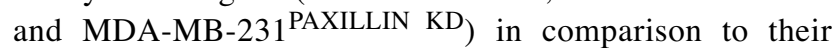
respective pEF6 plasmid controls (Figure 1E, F and G, $p=0.04,0.029$ and 0.029 , respectively).

Impact of paxillin knockdown on cell growth and matrix adhesion. To experimentally assess the impact of paxillin knockdown on PC-3, LNCaP and MDA-MB-231 cell growth rate, in vitro cell growth assays were performed (Figure 2A$\mathrm{C}$, respectively). Knockdown of paxillin appeared to influence the growth rate of the LNCaP PAXILLIN KD cell line which was found to be significantly elevated following 5-day 
A

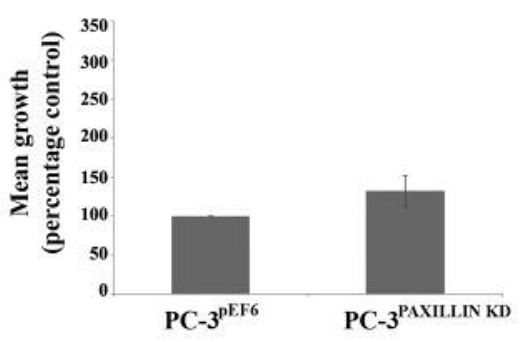

B

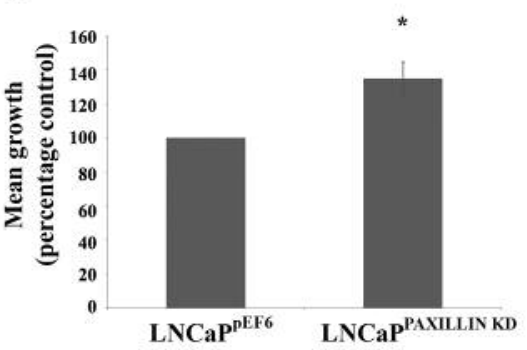

C

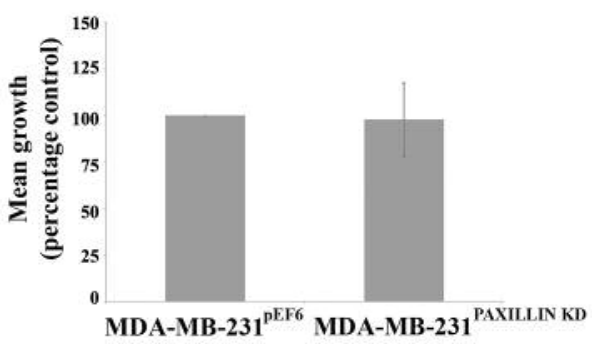

D

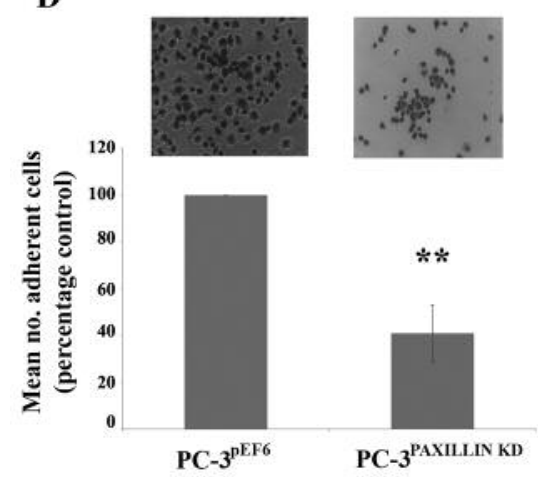

$\mathbf{E}$

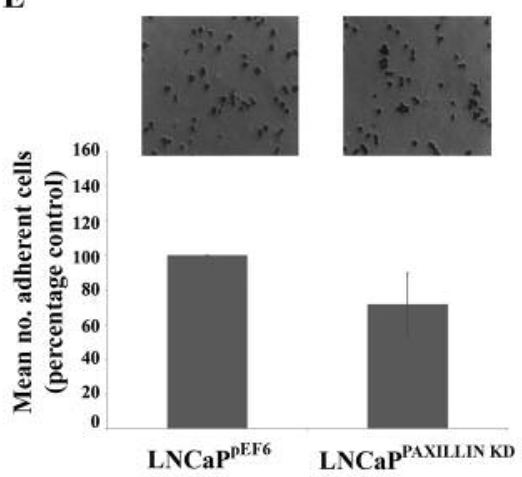

F

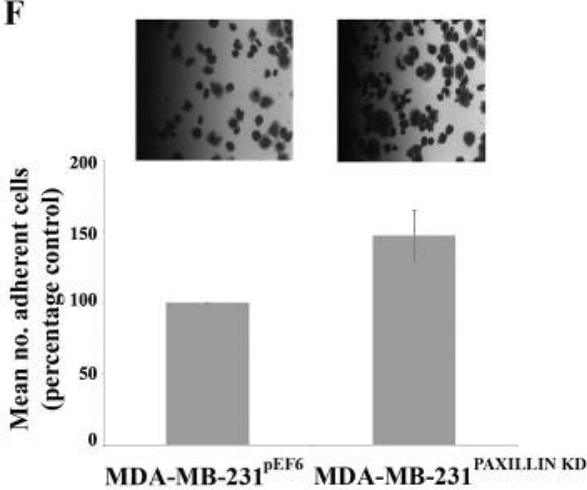

Figure 2. Impact of paxillin knockdown (KD) on cell growth and matrix adhesion. The growth of PC-3 (A), LNCaP (B) and MDA-MB-231 (C) cells was examined following suppression of paxillin, demonstrating a significant enhancement of growth of LNCaP cells over a 5-day incubation period. Similarly the capacity to adhere to Matrigel matrix, over a 45-minute incubation period, was also examined in PC-3 (D), LNCaP (E) and MDAMB-231 $(F)$ cells following suppression of paxillin, demonstrating reduced adherent capacity in the PC-3 cell line following paxillin suppression. Data shown represent the mean percentage relative to control values of three independent replicates \pm SEM. Representative images captured at $\times 200$ magnification are shown. Significantly different at $* p \leq 0.05$ and $* * p \leq 0.01$.

incubation in comparison to the $\mathrm{LNCaP}^{\mathrm{pEF} 6}$ control $(p=0.02)$. The knockdown of paxillin had no significant impact on the growth rate of either PC-3 or MDA-MB-231 cell lines over the 5-day incubation period. No significant changes in growth rates between any of the paxillin knockdown or pEF6 controls was seen over an initial 3-day incubation period ( $p>0.05$, data not shown).

Matrigel matrix cell adhesion assays were also conducted to establish the impact of paxillin knockdown on the cellmatrix adhesion of PC-3, LNCaP and MDA-MB-231 cells (Figure 2D-F, respectively). Knockdown of paxillin in $\mathrm{PC}-3$ cells negatively impacted on their ability to adhere to an artificial basement membrane ( $p=0.009)$ when compared to the attachment ability of the PC- $3^{\text {pEF6 }}$ control cell line. No significant differences were seen between $\mathrm{LNCaP}{ }^{\mathrm{pEF} 6}$ and LNCaP PAXILLIN KD or MDA-MB-231 ${ }^{\mathrm{pEF} 6}$ and MDA-MB$231^{\text {PAXILLIN KD }}$, however, a general increase in matrix adhesion was seen in MDA-MB-231 PAXILLIN KD, although this was just below the level of significance $(p=0.06)$.
Impact of paxillin knockdown on cellular invasion and migration. Matrigel invasion assays were undertaken to explore the impact of paxillin knockdown on the cellular invasiveness of PC-3, LNCaP and MDA-MB-231 cells (Figure 3A-C, respectively). No significant difference in invasive capacity was seen between PC-3 $3^{\text {pEF6 }}$ and PC-3 $3^{\text {PAXILLIN KD }}$ cells $(p=0.15)$ although levels were generally higher in PC-3 $3^{\text {PAXILLIN KD }}$. In turn, knockdown of paxillin in $\mathrm{LNCaP}$ cells resulted in a significant increase in invasive potential in comparison to control LNCaP ${ }^{\mathrm{pEF} 6}$ cells $(p=0.05)$. However, in MDA-MB-231 cells, suppression of paxillin reduced the invasiveness of this cell line compared to MDA-MB-231 ${ }^{\mathrm{pEF} 6}$ control cells, although this was not statistically significant $(p=0.08)$.

The impact of paxillin knockdown on the migratory rate of PC-3, LNCaP and MDA-MB-231 cells was also explored using a scratch wound assay (Figure 3D-F, respectively). Suppression of paxillin did not have a significant impact on the migratory capacity of any cell line in comparison to their respective pEF6 controls $(p>0.05)$. 


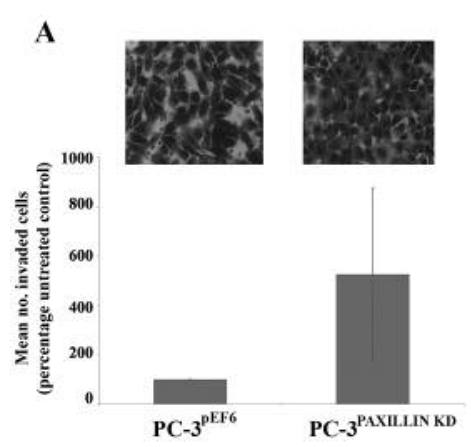

D

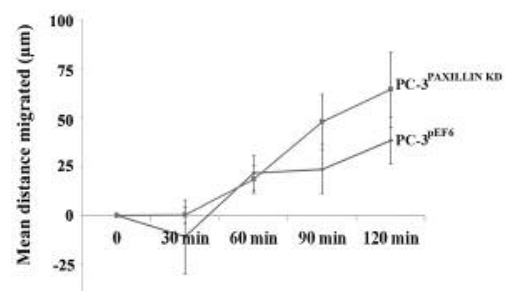

B

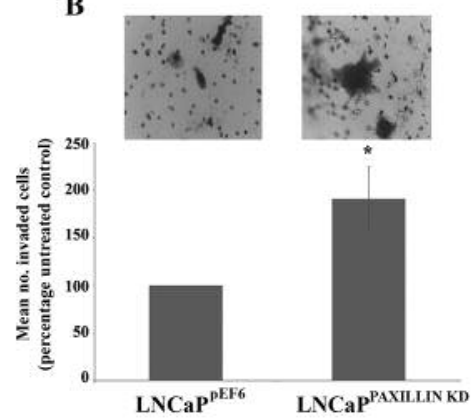

$\mathbf{E}$

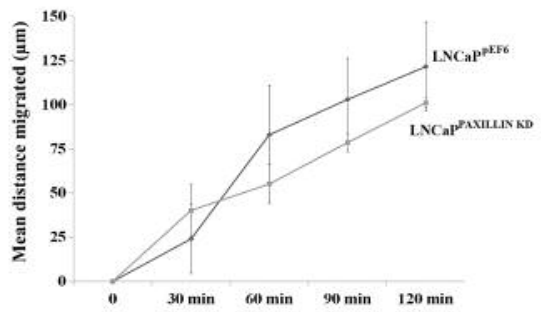

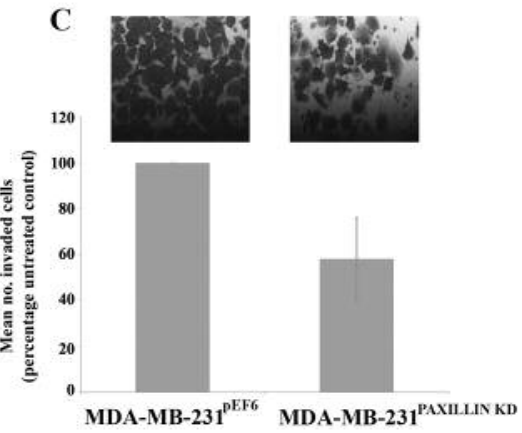

F

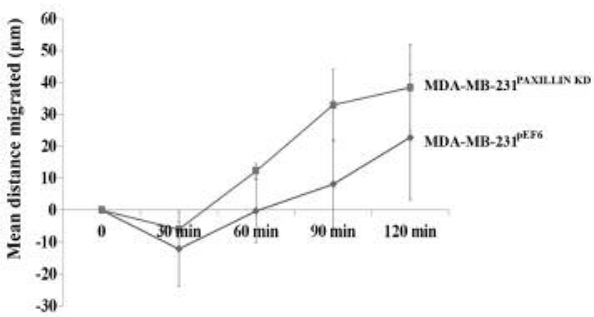

Figure 3. Impact of paxillin knockdown (KD) on cell invasion and migration. The invasive potential of PC-3 (A), LNCaP (B) and MDA-MB-231 (C) cell lines was examined following suppression of paxillin, demonstrating a significant increase in LNCaP invasion following paxillin suppression. Data shown represent the mean percentage relative to control values, following 3-day incubation, of three independent replicates \pm SEM. Cellular migration following paxillin knockdown was also examined in PC-3 (D), LNCaP (E) and MDA-MB-231 (F) cells, demonstrating no significant change in any cell line at any of the tested time points. Migration data represent the mean distance migrated between wound fronts over three independent replicates \pm SEM. Representative images captured at $\times 200$ magnification are shown. *Significantly different at $p \leq 0.05$.

Significance of paxillin in growth response to $H G F$ and $B M E$ treatments and FAK inhibition. To further explore the role of paxillin in the growth response to $\mathrm{HGF}$ and/or BME treatments and FAK inhibition, growth assays were conducted with different treatments/inhibitors (Figure 4).

For the PC-3 cell line, the suppression of paxillin brought about a number of differential responses to the different treatments (Figure $4 \mathrm{~A}$ and $\mathrm{B}$ ). In $\mathrm{PC}-3^{\mathrm{pEF} 6}$ cells, no significant alterations in 3-day growth were seen in response to $\mathrm{HGF}, \mathrm{BME}$ or combined $\mathrm{HGF}$ and BME treatments, although the addition of FAK inhibitor significantly enhanced growth for this incubation time in comparison to the untreated PC-3 $3^{\mathrm{pEF} 6}$ day 3 control. However, for PC$3^{\text {PAXILLIN KD }}$ cells, BME treatment alone and combined with HGF both brought about a significant increase in cell growth in comparison to the untreated PC- $3^{\text {PAXILLIN KD }}$ day 3 control $(p<0.05)$. These alterations did not continue over the course of the experiment and no significant differences were seen between treated PC-3 $3^{\text {PAXILLIN KD }}$ in comparison to untreated $\mathrm{PC}-3^{\mathrm{PAXILLIN}} \mathrm{KD}$ cells or between treated $\mathrm{PC}-3^{\mathrm{pEF} 6}$ and untreated $\mathrm{PC}-3^{\mathrm{pEF} 6}$ cells at the 5-day incubation point.
For the LNCaP model (Figure 4C and D), no significant differences in growth were observed between untreated LNCaPpEF6 cell and LNCaPpEF6 cells treated with HGF, BME, alone or in combination, or with FAK inhibitor at either of the respective time points and this was similar for LNCaPPAXILLIN KD cells with the exception of HGF treatments, which significantly reduced growth in comparison to untreated LNCaPPAXILLIN KD cells at each of the respective time points. Similarly, the only significant impact observed for the MDA-MB-231 models (Figure 4E and F) was upon 5-day HGF treatment of MDA-MB-231 ${ }^{\mathrm{pEF} 6}$ cells, bringing about a significant decrease in comparison to the 5-day untreated MDA-MB-231 ${ }^{\mathrm{pEF} 6}$ control.

Significance of paxillin on matrix adhesion in response to $H G F$ and BME treatments and FAK inhibition. The influence of individual treatments with HGF, BME, their combination, and FAK inhibitor on the matrix adhesion of PC-3 3 PAXILLIN KD, $\mathrm{LNCa}^{\text {PAXILLIN KD }}$ and MDA-MB-231 PAXILLIN KD and their respective controls $\left(\mathrm{PC}-3^{\mathrm{pEF} 6} \mathrm{LNCaP}{ }^{\mathrm{pEF} 6}\right.$ and MDA-MB$231^{\mathrm{pEF} 6}$ ) were experimentally verified in comparison to appropriate untreated controls (Figure 5). None of the knocked down cell lines treated with HGF exhibited significant changes 

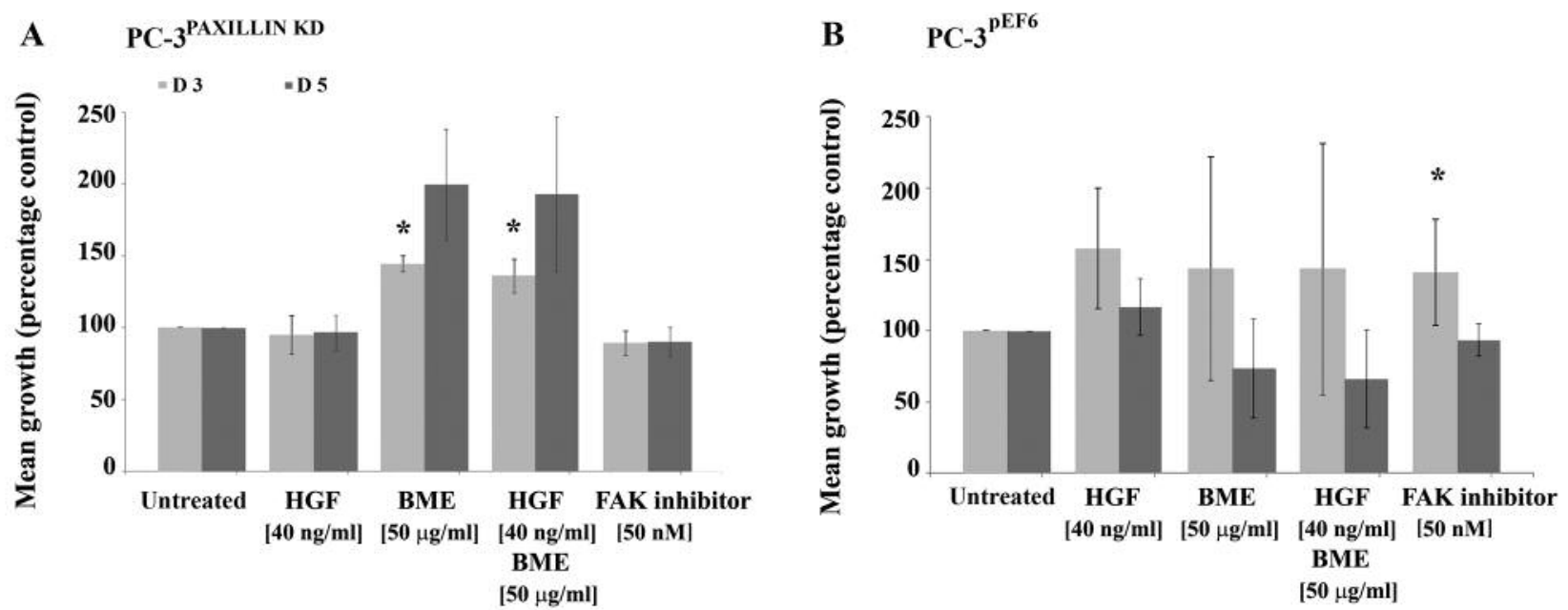

C LNCaP PAXILLIN KD

D LNCaP $^{\text {pEF6 }}$
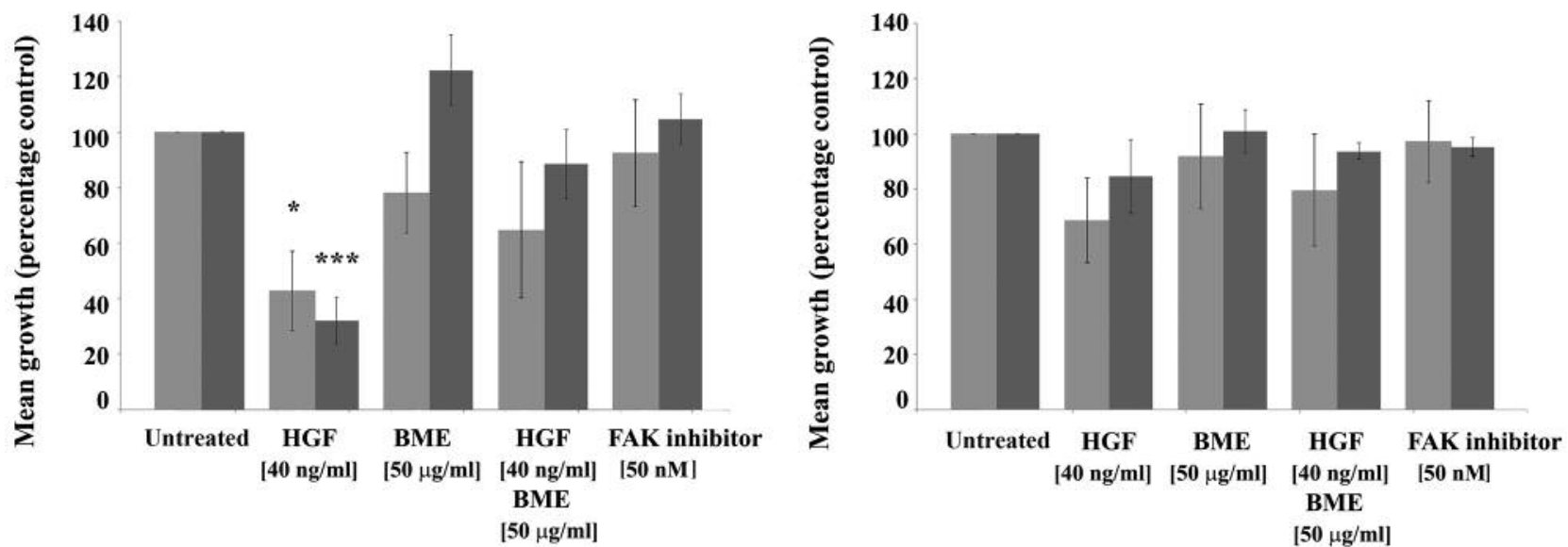

E MDA-MB-231 PAXILLIN KD

F MDA-MB-231 ${ }^{\text {pEF6 }}$
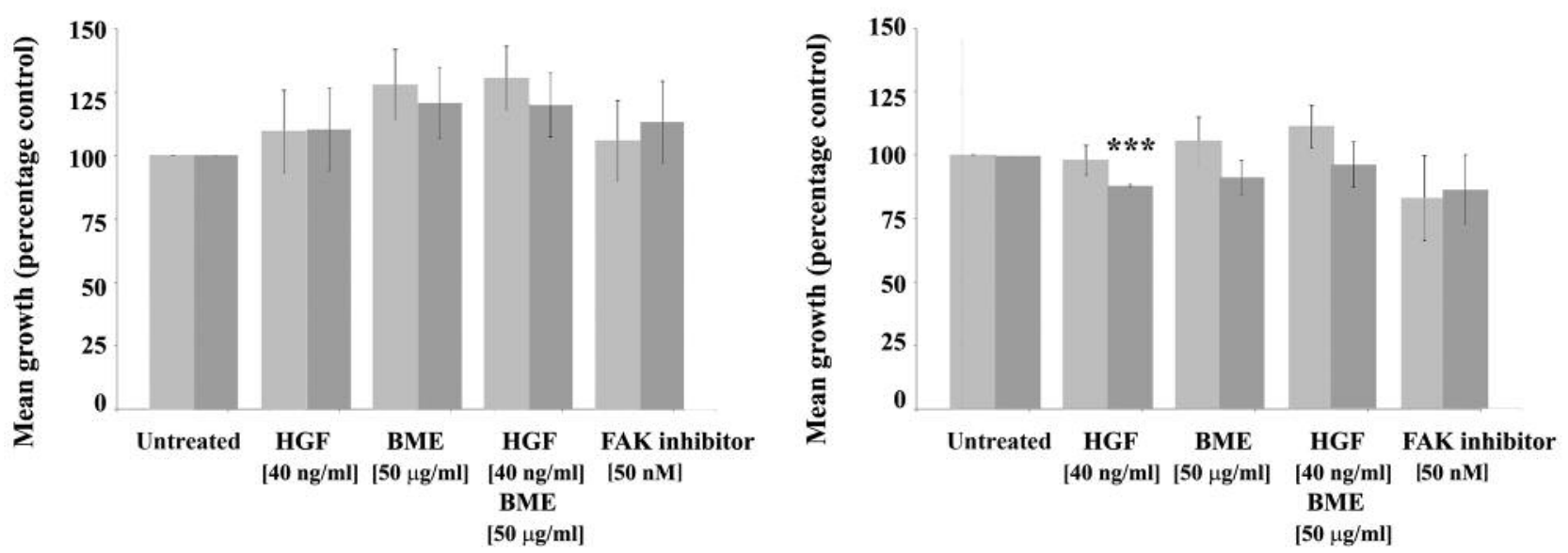

Figure 4. Impact of paxillin knockdown (KD) on the growth response to hepatocyte growth factor $(H G F)$ and bone matrix extract (BME) treatments, and focal adhesion kinase (FAK) inhibition. Differential responses to treatments were seen between PC-3PAXILLIN KD (A) and PC-3PEF6 (B) cells. Additionally, growth responses to HGF were also different between LNCaPPAXILLIN KD $(C)$ and LNCaPpEF6 (D) cells. Similar treatment responses were seen in MDA-MB-231PAXILLIN KD $(E)$ and MDA-MB-231pEF6 $(F)$ cells, with the exception of 5-day HGF treatment. Data shown are the mean percentage change in comparison to the untreated equivalent cell line at each individual incubation time and represent three independent replicates \pm SEM. Significantly different at $* p \leq 0.05, * * p \leq 0.01$ and $* * * p \leq 0.001$. 
in their adhesion ability (Figure 5A, C and E). However, the effect of treatment of PC-3 3 PAXILLIN KD cells with BME alone $(p=0.05)$, as well as in combination with HGF ( $p=0.01)$, was found to be significant in both cases. It was observed that both treatments greatly lowered the adhesive ability of PC$3^{\text {PAXILLIN KD }}$ cells when compared to untreated PC-3 ${ }^{\text {PAXILLIN }}$ $\mathrm{KD}$ cells (Figure 5A). In addition, the adhesive ability of LNCaP PAXILLIN KD cells was significantly reduced in response to $\operatorname{BME}(p=0.04)$ and combined HGF and BME $(p=0.02)$ treatments when compared to untreated LNCaPPAXILLIN KD cells (Figure 5C). No differences were observed for MDA-MB$231^{\text {PAXILLIN KD }}$ cells when stimulated with BME alone nor in combination with HGF (Figure 5E). It was also observed that FAK inhibitor appeared to significantly inhibit the matrixattachment ability of PC-3 $3^{\text {PAXILLIN KD }}$ cells $(p<0.001 v s$. untreated PC-3 ${ }^{\text {PAXILLIN KD }}$ ) and brought about near significant reductions in the matrix adhesion of LNCaPPAXILLIN KD $(p=0.06$ vs. untreated LNCaP PAXILLIN KD) (Figure 5A and C) but had no effect on the matrix-attachment ability of MDAMB-231 PAXILLIN KD cells (Figure 5E). There were no statistically significant differences between untreated MDAMB-231 PAXILLIN KD cells and any of the treatment groups (Figure 5E). In the PC-3 $3^{\mathrm{pEF} 6}$ control cells, individual treatments with $\mathrm{HGF}$ and BME did not prove to have a significant impact on cell adherence when compared to their untreated control (Figure 5B). However, the combination of HGF and BME treatments, as well as the treatment with FAK inhibitor, significantly lowered their ability to adhere to the artificial basement membrane $(p=0.04$ and 0.004 respectively $v s$. untreated $\mathrm{PC}-3^{\mathrm{pEF} 6}$ ) (Figure $5 \mathrm{~B}$ ). On the contrary, the matrix-attachment ability of control $\mathrm{LNCaP}^{\mathrm{pEF} 6}$ cells was significantly reduced by individual treatments with HGF $(p=0.004)$ and BME $(p=0.015)$ and also by the combined HGF and BME treatment $\left(p=0.014 v s\right.$. untreated $\left.\mathrm{LNCaP}^{\mathrm{pEF} 6}\right)$ (Figure 5D). FAK inhibition also reduced $\mathrm{LNCaP}^{\mathrm{pEF} 6}$ matrix adhesion, though this did not quite reach significance $(p=0.06$ $v s$. untreated $\left.\mathrm{LNCaP}^{\mathrm{pEF} 6}\right)$. Finally, the matrix-attachment ability of MDA-MB-231 ${ }^{\text {pEF6 }}$ cells was not affected by treatments with HGF or BME, their combination, nor FAK inhibitor (Figure 5F).

Significance of paxillin on the invasive response to $H G F$ and $B M E$ treatments and FAK inhibition. The invasive response to individual treatments with $\mathrm{HGF}, \mathrm{BME}$, the combination of both HGF and BME, and FAK inhibitor in PC-3 3 PAXILLINKD, LNCaPPAXILLINKD and MDA-MB-231 PAXILLINKD and their respective controls (PC-3 ${ }^{\text {pEF6 }} \mathrm{LNCaP}{ }^{\mathrm{pEF} 6}$ and MDA-MB$231^{\mathrm{pEF} 6}$ ) were experimentally verified in comparison to appropriate untreated controls (Figure 6). PC-3 $3^{\text {PAXILLIN KD }}$ cells did not exhibit any significant changes in invasiveness, in comparison to untreated PC-3 ${ }^{\text {PAXILLIN KD }}$ cells, following any of the treatments, although increased invasion was generally seen in response to $\mathrm{HGF}, \mathrm{BME}$ or their combination. Addition of the FAK inhibitor similarly, did not have a significant impact on the invasiveness of PC$3^{\text {PAXILLIN KD }}$ cells (Figure 6A). Similarly, by comparison to the untreated group, the invasiveness of $\mathrm{PC}-3^{\mathrm{pEF} 6}$ cells was not affected by individual treatment with $\mathrm{BME}$, the combination of $\mathrm{HGF} / \mathrm{BME}$, nor by FAK inhibition, although it was generally enhanced. However, HGF treatment significantly increased the ability of PC-3 ${ }^{\text {pEF6 }}$ cells to invade the artificial basement membrane $(p=0.016 v s$. untreated PC$3^{\mathrm{pEF} 6}$ ) (Figure 6B). LNCaP PAXILLIN KD cells, in contrast, responded to HGF (Figure 6C) demonstrating a highly significant decrease in the level of invasion following this treatment ( $p=0.001 v s$. untreated LNCaPPAXILLIN KD cells). Stimulation with the combination of HGF and BME also seemed to reduce the invasiveness of LNCaP PAXILLIN KD cells ( $p=0.02 v s$. untreated LNCaP PAXILLIN KD cells) (Figure $6 \mathrm{C})$. None of the treatments appeared to influence the invasive capacities of $\mathrm{LNCaP}^{\mathrm{pEF} 6}$ cells and no significant differences were noted between treated and untreated LNCaPpEF6 cells (Figure 6D). No significant changes affecting the invasive ability of the MDA-MB-231 PAXILLIN $\mathrm{KD}$ cell line were seen following treatments with HGF, combined $\mathrm{HGF} / \mathrm{BME}$ or FAK inhibitor. However, a significant decrease in invasiveness of MDA-MB$231^{\text {PAXILLIN KD }}$ cells was observed upon stimulation with BME alone $(p=0.007 v s$. untreated MDA-MB-231 PAXILLIN $\mathrm{KD}$ ) (Figure 6E). None of the treatments brought about a significant change in the invasive capacitiy of MDA-MB$231^{\mathrm{pEF} 6}$ cells in comparison to untreated MDA-MB-231 ${ }^{\mathrm{pEF} 6}$ cells, except for the addition of FAK inhibitor, which significantly reduced invasiveness of this group ( $p=0.025 \mathrm{vs}$. untreated MDA-MB-231 ${ }^{\mathrm{pEF} 6}$ cells) (Figure 6F).

Significance of paxillin on the migratory response to $H G F$ and BME treatments and FAK inhibition. The effects of different treatments on the motility of paxillin knockdown and control pEF6 cells were analysed using a multiple comparison procedure (Figure 7). For each cell line, the untreated group was compared separately to each treatment group. Statistical analysis did not reveal any significant changes in the motility of PC-3 $3^{\text {PAXILLIN KD }}$ cells between untreated cells and any of the treatments used for the experiment over a 2 -h period (Figure 7A). Moreover, no significant increase or decrease in motility upon any of the treatments was observed for MDA-MB-231 PAXILLIN KD cells (Figure 7E). The same multiple comparison test was performed for PC-3 $3^{\mathrm{pEF} 6}$ cells and significant increases in the motility of this cell line was seen upon HGF treatment $(p<0.001)$, BME treatment $(p=0.04)$, combined HGF and BME treatment $(p<0.001)$ and following the addition of FAK inhibitor $(p=0.004)$ when compared to untreated PC$3^{\mathrm{pEF} 6}$ cells (Figure 7B). Similarly, increases in motility were observed between untreated and HGF or HGF/BME treated 
(A)

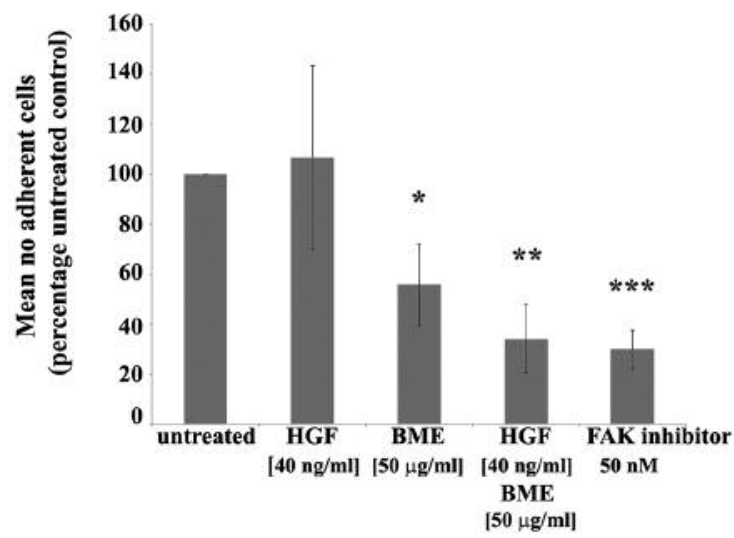

(C) LNCaP ${ }^{\text {PAXILLIN KD }}$

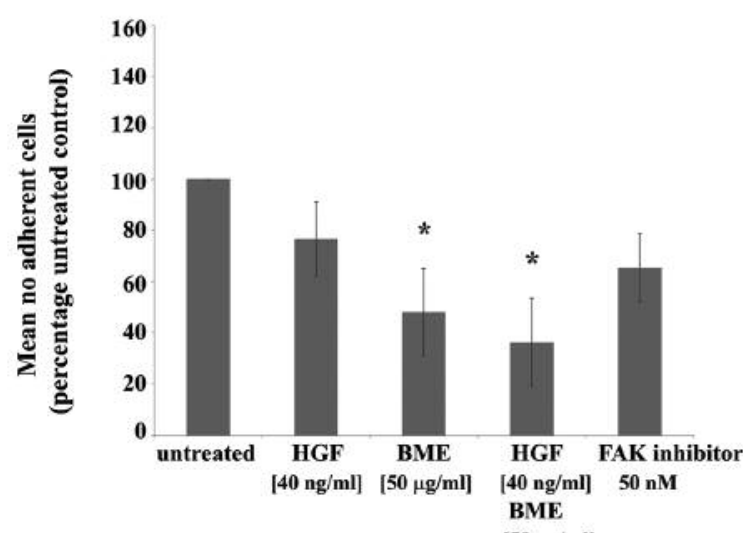

(E)

MDA-MB-231 ${ }^{\text {PAXILLIN KD }}$

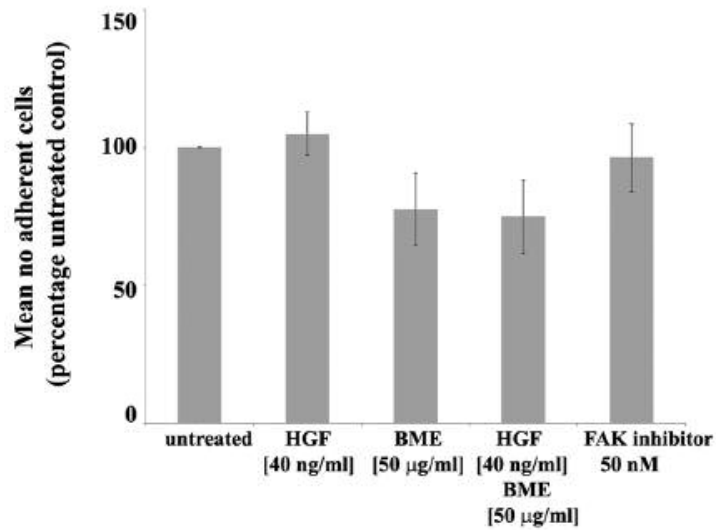

(B)

$\mathrm{PC}-3^{\mathrm{pEF} 6}$

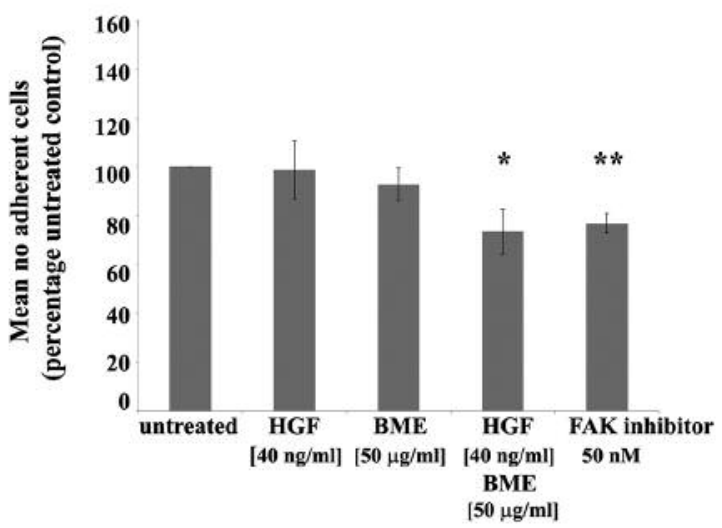

(D)

$\mathrm{LNCaP}^{\mathrm{pEF} 6}$

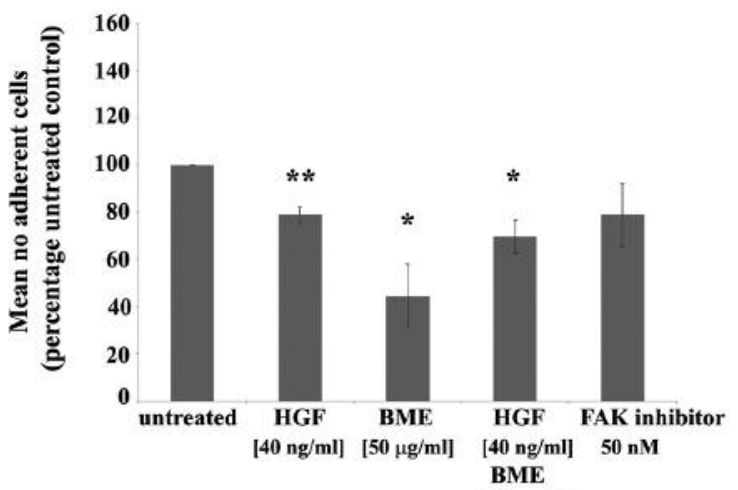

[50 $\mu \mathrm{g} / \mathrm{ml}]$

(F)

MDA-MB-231 ${ }^{\text {PEF } 6}$

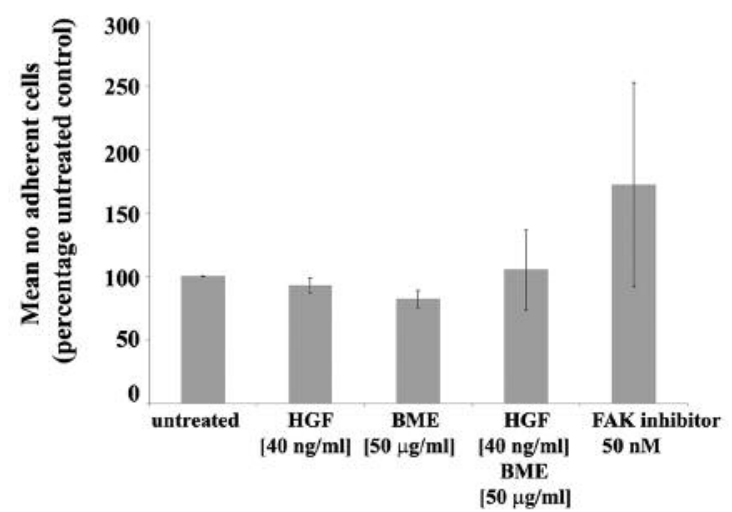

Figure 5. Impact of paxillin knockdown (KD) on matrix adhesion in response to hepatocyte growth factor (HGF) and bone matrix extract (BME) treatments, and focal adhesion kinase (FAK) inhibition. Treatment of PC-3PAXILLIN KD cells (A) with HGF, BME or a combination of HGF and BME brought about a greater inhibition of matrix adhesion in comparison to PC-3PEF6 cells (B). Reductions in LNCaPPAXILLIN KD (C) matrix adhesion following $B M E$, combined HGF/BME, and HGF treatment were observed and this was similar in LNCaPpEF6 (D) cells, although significant results were seen in this line in relation to HGF treatment. No significant differential responses to the different treatments were seen between MDA-MB$231^{\text {PAXILLIN KD }}(E)$ and MDA-MB-231pEFG $(F)$. Data shown are the mean percentage change in comparison to the untreated equivalent cell line of three independent replicates \pm SEM. Significantly different at $* p \leq 0.05, * * p \leq 0.01$ and $* * * p \leq 0.001$. 
MDA-MB-231 ${ }^{\mathrm{pEF} 6}$ cells $(p<0.001$ in both cases). However, statistical analysis showed no significant changes in the motility of MDA-MB-231 $1^{\mathrm{pEF} 6}$ cells when treated to BME nor with FAK inhibitor when compared to untreated MDAMB-231 ${ }^{\mathrm{pEF} 6}$ cells over this incubation time (Figure 7F). The effects of the individual treatments on LNCaP PAXILLIN KD and $\mathrm{LNCaP}^{\mathrm{pEF} 6}$ cell motility were also analysed using a multiple comparison procedure (Figure $7 \mathrm{C}$ and D). A significant increase in the motility of the paxillin knockdown cells treated with BME, HGF/BME and FAK inhibitor over the course of $2 \mathrm{~h}$ was shown (all $\mathrm{p}<0.001 v s$. untreated $\mathrm{LNCaP}^{\text {PAXILLIN KD }}$ cells). Incubation with HGF did not influence the migratory ability of LNCaP ${ }^{\text {PAXILLIN KD }}$ cells (Figure 7C). Statistical analysis revealed no significant changes in the motility of $\mathrm{LNCaP}{ }^{\mathrm{pEF} 6}$ cells over the experimental course when these cells were treated with HGF, BME, a combination of both HGF and BME, nor with FAK inhibitor when compared to untreated $\mathrm{LNCaP}^{\mathrm{pEF} 6}$ cells (Figure 7D).

\section{Discussion}

Bone is one of the most common locations for metastasis (27). While any type of cancer is capable of forming metastatic tumours within bone, the microenvironment of the marrow favours particular types of cancer, including breast, lung and prostate cancer (28). Once tumour metastasises to bone, it induces significant skeletal remodelling, fractures, pain, and anaemia (29) and becomes a major cause of morbidity and mortality. The local tumour microenvironment has been shown to influence tumour malignancy. Signals from the extracellular environment are transmitted through focal adhesions, modulating intracellular signal transduction pathways to regulate processes such as cell migration and changes in gene expression (30). Key focal adhesion proteins, including paxillin, vimentin and talin (31-33), coordinate downstream signalling events (34) between integrins and the actin cytoskeleton (35), which plays an important role in abnormal growth, invasion, and metastasis of malignant tumours (36-38). Throughout the literature, paxillin has been described as playing complex roles in cancer and cancer progression, being found to be differentially expressed in a variety of invasive/metastatic cancer types (12-16). Several studies have demonstrated a link between paxillin and malignant progression (39-42). Therefore paxillin appears to play a complex role in cancer invasiveness that may be linked to the particular cancer types. In the current study, we suppressed paxillin expression in $\mathrm{PC}-3, \mathrm{LNCaP}$ and MDA-MB-231 cell lines and characterised the function of such mutants, as well as their responsiveness to HGF, bone matrix-like conditions and in conjunction with FAK inhibition. Knockdown of paxillin was seen to have differential effects in the different cell lines. In the PC-3 osteolytic model, suppression of paxillin brought about a decrease in matrix adhesion and a general increase in cellular invasion, and similar trends were seen in the mixed osteolytic/osteoblastic LNCaP model, where matrix adhesion was generally reduced and invasive capacity enhanced following paxillin knockdown, although the growth rate of this model was also increased. In contrast to this, in the MDA-MB-231 breast cancer model, suppression of paxillin enhanced matrix-adhesion and decreased invasion, although in both cases this was not seen to be significant. Hence our study suggests potential cell line- or cancer type-specific roles for paxillin. Changes in expression or localisation of paxillin and FAK are frequently associated with changes in the metastatic potential of cancer cells and previous work in our laboratories has demonstrated such changes to paxillin and FAK following alterations in cellular motility and adhesion in response to the targeting or overexpression of a variety of molecules in breast and prostate cancer models $(17,43,44)$. Additionally, changes in paxillin expression or phosphorylation have also been implicated in resistance to therapies such as cisplatin and cetuximab in non-small cell lung cancer and colorectal cancer $(19,20)$.

Evidence indicates that pathways for integrin signalling and growth factor signalling are linked. Integrins co-localize and co-precipitate with several growth factor receptors, including the epidermal growth factor receptor (EGFR) $(10,33)$ and other studies have indicated that HGF signalling can crosstalk with integrin signalling by converging to some intracellular signalling molecules, such as FAK and proto-oncogene tyrosine-protein kinase $\mathrm{Src}$ (Src), which further transduce signals to downstream effectors (45). In the current study, we aimed to further explore the role of paxillin in the responsiveness of prostate and breast cancer cells to HGF and also to bone-like conditions, mimicked by our BME resource. Furthermore, we also explored the FAK-paxillin relationship through the addition of a FAK small-molecule inhibitor. In the functional assays, a number of differential trends were observed between pEF6 control and paxillin knockdown cells. Paxillin suppression appeared to influence the growth, invasiveness, matrix-adherence and motility of these cell lines in response to HGF, BME and FAK inhibition, although such responses appeared to be cell line-/treatment type-specific and this itself is likely due to the inherent differences between these cell types and their aggressiveness. Hence, our current data indicate that paxillin is not only important in a variety of functional characteristics linked to the metastatic potential of cells, but is also involved in regulating the response of cells to a number of external stimuli such as HGF and bone-like conditions. Previous studies have highlighted potential links between paxillin and HGF, where HGF has been found to enhance aggressive metastatic traits in prostate and breast cancer cells, such as motility, enhanced focal adhesion 

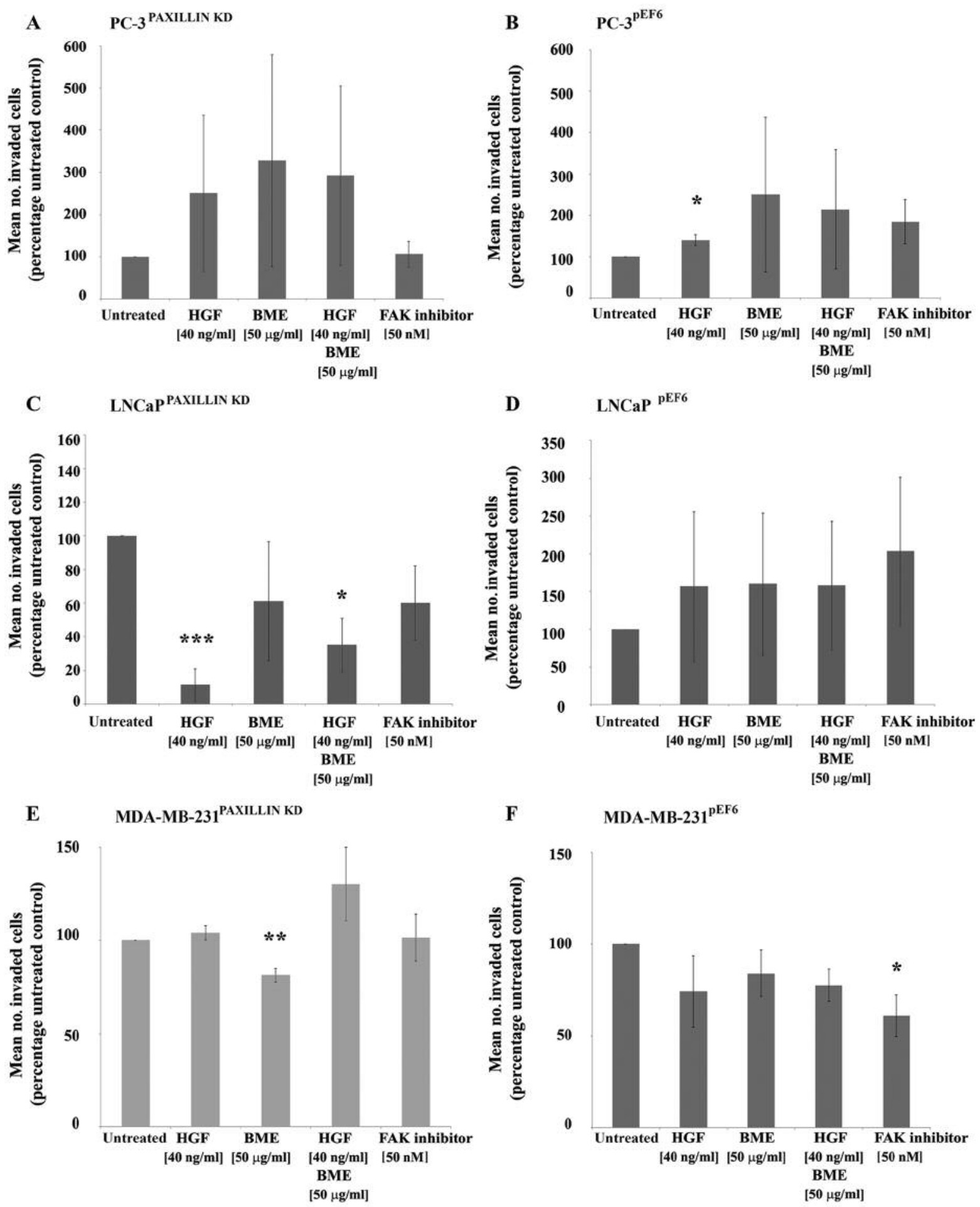

Figure 6. Impact of paxillin knockdown (KD) on cellular invasion in response to hepatocyte growth factor (HGF) and bone matrix extract (BME) treatments, and focal adhesion kinase (FAK) inhibition. Similar increases in invasion were seen in PC-3PAXILLIN KD (A) and PC-3PEF6 (B) in response to $H G F, B M E$ and mixed $H G F / B M E$, although HGF treatment caused a significant increase following HGF treatment and a general increase following FAK inhibition. All treatments brought about a general decrease in LNCaPPAXILLIN KD $(C)$ invasion, although only the effects of HGF treatment and combined HGF/BME treatment were found to be significant. In contrast, general increases in invasion following all treatments were seen in LNCaPpEF6 cells $(D)$, although none were found to be statistically significant. Only BME treatment in MDA-MB-231PAXILLIN KD (E) and FAK inhibition in MDA-MB-231pEFG $(F)$ cells brought about significant decreases in these lines. Data shown are the mean percentage change in comparison to the untreated equivalent cell line of three independent replicates \pm SEM. Significantly different at $* p \leq 0.05$, ** $p \leq 0.01$ and $* * * p \leq 0.001$. 

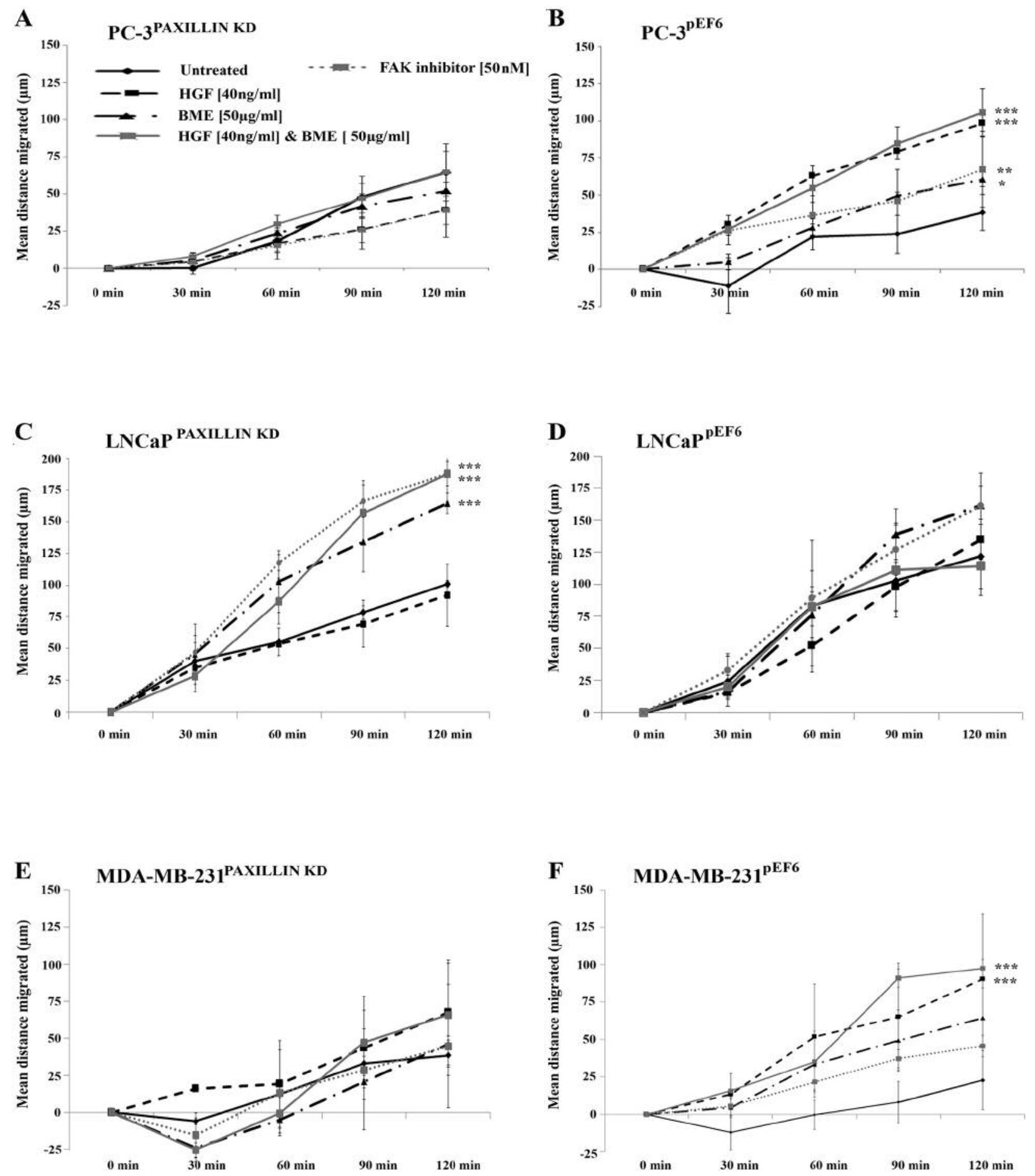

Figure 7. Impact of paxillin knockdown (KD) on cellular migration in response to hepatocyte growth factor (HGF) and bone matrix extract (BME) treatments, and focal adhesion kinase (FAK) inhibition. None of the treatments resulted in any significant changes in the motility rates of PC$3^{P A X I L L I N} K D(A)$, whereas all treatments significantly enhanced migration of PC-3PEF6 cells $(B)$. For the LNCaPPAXILLIN KD cell line (C) all treatments apart from HGF brought about a significant enhancement of migration over the experimental course, although for the LNCaPpEF6 cell line $(D)$ no significant effects were observed following any of the treatments. No significant changes in migration over the experimental course were seen in MDA-MB-231PAXILLIN KD cells (E) and, in contrast to this, both HGF and combined HGF/BME significantly enhanced the migration of $M D A-M B-231^{p E F 6}$ cells $(F)$. Migration data represent mean distance migrated between wound fronts for three independent replicates \pm SEM. Statistical comparisons are made with the untreated equivalent cell line. Significantly different at $* p \leq 0.05, * * p \leq 0.01, * * * p \leq 0.001$. 
formation and paxillin phosphorylation, and such events were inhibited by NK4, a HGF antagonist comprising N-terminal hairpin domain and four kringle domains of $\operatorname{HGF}(46,47)$. There is also some evidence to implicate paxillin and FAK in bone metastasis, and these molecules can be altered in response to key bone morphogenetic protein family members $(17,44)$. Additionally, another study, looking at the bone metastasis derived C4-2B cell line, found a key role for the integrin $\alpha 2$ subunit, paxillin, FAK, Src, Ras-related C3 botulinum toxin substrate (RAC) and c-Jun N-terminal kinases (JNK) as well as matrix metalloproteinase- 2 and -9 in the attachment and invasion of collagen I (48). Taken together, our current data, support a complex role for paxillin in regulating key metastatic traits, as well as in mediating responses to various extracellular signals, although this may be cell-/ cancer type-specific, and also suggest potential roles for paxillin in regulating the dissemination of cancer cells from the primary tumour through to the establishment within the bone environment.

\section{Acknowledgements}

The Authors wish to thank Cancer Research Wales for supporting this study.

\section{References}

1 Wolff JM, Zimny M, Borchers $\mathrm{H}$, Wildberger J, Buell U and Jakse G: Is prostate-specific antigen a reliable marker of bone metastasis in patients with newly diagnosed cancer of the prostate? Eur Urol 33: 376-381, 1998.

2 Ho CC, Seong PK, Zainuddin ZM, Abdul Manaf MR, Parameswaran $M$ and Razack AH: Retrospective study of predictors of bone metastasis in prostate cancer cases. Asian Pac J Cancer Prev 14: 3289-3292, 2013.

3 Roodman GD: Mechanisms of bone metastasis. N Engl J Med 350: 1655-1664, 2004.

4 Morgans AK and Smith MR: Bone-targeted agents: preventing skeletal complications in prostate cancer. Urol Clin North Am 39: 533-546, 2012.

5 Scott LJ, Clarke NW, George NJ, Shanks JH, Testa NG and Lang SH: Interactions of human prostatic epithelial cells with bone marrow endothelium: binding and invasion. $\mathrm{Br} \mathrm{J}$ Cancer 84: 1417-1423, 2001

6 Jacobsen K, Kravitz J, Kincade PW and Osmond DG: Adhesion receptors on bone marrow stromal cells: in vivo expression of vascular cell adhesion molecule-1 by reticular cells and sinusoidal endothelium in normal and gamma-irradiated mice. Blood 87: 73-82, 1996.

7 Nakamura T: Molecular characterization of hepatocyte growth factor (HGF). Seikagaku 61: 1243-1247, 1989.

8 Gherardi E and Stoker M: Hepatocytes and scatter factor. Nature 346: 228,1990 .

9 Shaharabany M, Abramovitch R, Kushnir T, Tsarfaty G, RavidMegido M, Horev J, Ron R, Itzchak Y and Tsarfaty I: In vivo molecular imaging of met tyrosine kinase growth factor receptor activity in normal organs and breast tumors. Cancer Res 61 : 4873-4878, 2001
10 Turner CE: Paxillin and focal adhesion signalling. Nat Cell Biol 2: E231-236, 2000.

11 Mazaki Y, Hashimoto S and Sabe H: Monocyte cells and cancer cells express novel paxillin isoforms with different binding properties to focal adhesion proteins. J Biol Chem 272: 74377444, 1997.

12 Li BZ, Lei W, Zhang CY, Zhou F, Li N, Shi SS, Feng XL, Chen ZL, Hang J, Qiu B, Wan JT, Shao K, Xing XZ, Tan XG, Wang $\mathrm{Z}$, Xiong $\mathrm{MH}$ and $\mathrm{He} \mathrm{J}$ : Increased expression of paxillin is found in human oesophageal squamous cell carcinoma: a tissue microarray study. J Int Med Res 36: 273-278, 2008.

13 Cai HX, Yang LC, Song XH, Liu ZR, Chen YB and Dong GK: Expression of paxillin and FAK mRNA and the related clinical significance in esophageal carcinoma. Mol Med Rep 5: 469-472, 2012.

14 Zhao CJ, Du SK, Dang XB and Gong M: Expression of Paxillin is Correlated with Clinical Prognosis in Colorectal Cancer Patients. Med Sci Monit 21: 1989-1995, 2015.

$15 \mathrm{Wu}$ DW, Cheng YW, Wang J, Chen CY and Lee H: Paxillin predicts survival and relapse in non-small cell lung cancer by microRNA-218 targeting. Cancer Res 70: 10392-10401, 2010.

16 Short SM, Yoder BJ, Tarr SM, Prescott NL, Laniauskas S, Coleman KA, Downs-Kelly E, Pettay JD, Choueiri TK, Crowe JP, Tubbs RR, Budd TG and Hicks DG: The expression of the cytoskeletal focal adhesion protein paxillin in breast cancer correlates with HER2 overexpression and may help predict response to chemotherapy: a retrospective immunohistochemical study. Breast J 13: 130-139, 2007.

17 Bokobza SM, Ye L, Kynaston HG and Jiang WG: Growth and differentiation factor-9 promotes adhesive and motile capacity of prostate cancer cells by up-regulating FAK and Paxillin via Smad dependent pathway. Oncol Rep 24: 1653-1659, 2010.

18 Fernando HS, Sanders AJ, Kynaston HG and Jiang WG: WAVE3 is associated with invasiveness in prostate cancer cells. Urol Oncol 28: 320-327, 2010.

$19 \mathrm{Wu}$ DW, Wu TC, Wu JY, Cheng YW, Chen YC, Lee MC, Chen $\mathrm{CY}$ and Lee H: Phosphorylation of paxillin confers cisplatin resistance in non-small cell lung cancer via activating ERKmediated Bcl-2 expression. Oncogene 33: 4385-4395, 2014.

$20 \mathrm{Du}$ C, Wang X, Zhang J, Liu X, Zhu J and Liu Y: Paxillin is positively correlated with the clinicopathological factors of colorectal cancer and knockdown of paxillin improves sensitivity to cetuximab in colorectal cancer cells. Oncol Rep 35: 409-417, 2016.

21 Davies S and Jiang WG: ALCAM, activated leukocyte cell adhesion molecule, influences the aggressive nature of breast cancer cells, a potential connection to bone metastasis. Anticancer Res 30: 1163-1168, 2010.

22 Jiang WG, Grimshaw D, Lane J, Martin TA, Abounader R, Laterra $J$ and Mansel RE: A hammerhead ribozyme suppresses expression of hepatocyte growth factor/scatter factor receptor cMET and reduces migration and invasiveness of breast cancer cells. Clin Cancer Res 7: 2555-2562, 2001.

23 Jiang WG, Davies G, Martin TA, Parr C, Watkins G, Mason MD, Mokbel K and Mansel RE: Targeting matrilysin and its impact on tumor growth in vivo: the potential implications in breast cancer therapy. Clin Cancer Res 11: 6012-6019, 2005.

24 Sanders AJ, Ye L, Li J, Mason MD and Jiang WG: Tumour angiogenesis and repulsive guidance molecule b: a role in HGF- and BMP-7-mediated angiogenesis. Int J Oncol 45: 1304-1312, 2014. 
25 Jiang WG, Hiscox S, Hallett MB, Horrobin DF, Mansel RE and Puntis MC: Regulation of the expression of E-cadherin on human cancer cells by gamma-linolenic acid (GLA). Cancer Res 55: 5043-5048, 1995.

26 Jiang WG, Hiscox SE, Parr C, Martin TA, Matsumoto K, Nakamura $\mathrm{T}$ and Mansel RE: Antagonistic effect of NK4, a novel hepatocyte growth factor variant, on in vitro angiogenesis of human vascular endothelial cells. Clin Cancer Res 5: 3695-3703, 1999.

27 Coleman RE: Clinical features of metastatic bone disease and risk of skeletal morbidity. Clin Cancer Res 12: 6243s-6249s, 2006.

28 Guise T: Examining the metastatic niche: targeting the microenvironment. Semin Oncol 37(Suppl 2): S2-14, 2010.

29 Jimenez-Andrade JM, Mantyh WG, Bloom AP, Ferng AS, Geffre CP and Mantyh PW: Bone cancer pain. Ann NY Acad Sci 1198: 173-181, 2010.

30 Hynes RO: Integrins: bidirectional, allosteric signaling machines. Cell 110: 673-687, 2002.

31 Brown MC and Turner CE: Paxillin: adapting to change. Physiol Rev 84: 1315-1339, 2004.

32 Deakin NO and Turner CE: Paxillin comes of age. J Cell Sci 121: 2435-2444, 2008.

33 Turner CE: Paxillin interactions. J Cell Sci 113 Pt 23: 41394140, 2000.

34 Deakin NO, Pignatelli J and Turner CE: Diverse roles for the paxillin family of proteins in cancer. Genes Cancer 3: 362-370, 2012.

35 Desiniotis A and Kyprianou N: Significance of talin in cancer progression and metastasis. Int Rev Cell Mol Biol 289: 117-147, 2011.

36 Kudo Y, Kitajima S, Ogawa I, Hiraoka M, Sargolzaei S, Keikhaee MR, Sato S, Miyauchi M and Takata T: Invasion and metastasis of oral cancer cells require methylation of E-cadherin and/or degradation of membranous beta-catenin. Clin Cancer Res 10: 5455-5463, 2004.

37 Kumar R, Gururaj AE and Barnes CJ: p21-activated kinases in cancer. Nat Rev Cancer 6: 459-471, 2006.

38 Lo SH and Chen LB: Focal adhesion as a signal transduction organelle. Cancer Metastasis Rev 13: 9-24, 1994.

39 Salgia R, Li JL, Ewaniuk DS, Wang YB, Sattler M, Chen WC, Richards W, Pisick E, Shapiro GI, Rollins BJ, Chen LB, Griffin JD and Sugarbaker DJ: Expression of the focal adhesion protein paxillin in lung cancer and its relation to cell motility. Oncogene 18: 67-77, 1999.

40 Jagadeeswaran R, Surawska H, Krishnaswamy S, Janamanchi V, Mackinnon AC, Seiwert TY, Loganathan S, Kanteti R, Reichman T, Nallasura V, Schwartz S, Faoro L, Wang YC, Girard L, Tretiakova MS, Ahmed S, Zumba O, Soulii L, Bindokas VP, Szeto LL, Gordon GJ, Bueno R, Sugarbaker D, Lingen MW, Sattler M, Krausz T, Vigneswaran W, Natarajan V, Minna J, Vokes EE, Ferguson MK, Husain AN and Salgia R: Paxillin is a target for somatic mutations in lung cancer: implications for cell growth and invasion. Cancer Res 68: 132-142, 2008.
41 Kuroda N, Guo L, Toi M, Naruse K, Miyazaki E, Hayashi Y, Yoshikawa C, Ashida S, Shuin T and Enzan H: Paxillin: application of immunohistochemistry to the diagnosis of chromophobe renal cell carcinoma and oncocytoma. Appl Immunohistochem Mol Morphol 9: 315-318, 2001.

42 Pelagalli A, Scibelli A, Lombardi P, d'Angelo D, Tortora G, Staiano $\mathrm{N}$ and Avallone L: Expression of the focal adhesion protein paxillin in normal and breast cancer tissues. Vet Res Comm 27(Suppl 1): 343-346, 2003.

$43 \mathrm{Li} \mathrm{J}$, Ye L, Sanders AJ and Jiang WG: Repulsive guidance molecule B (RGMB) plays negative roles in breast cancer by coordinating BMP signaling. J Cell Biochem 113: 2523-2531, 2012.

44 Ye L, Lewis-Russell JM, Kynaston H and Jiang WG: Endogenous bone morphogenetic protein-7 controls the motility of prostate cancer cells through regulation of bone morphogenetic protein antagonists. J Urol 178: 1086-1091, 2007.

45 Chan KT, Cortesio CL and Huttenlocher A: FAK alters invadopodia and focal adhesion composition and dynamics to regulate breast cancer invasion. J Cell Biol 185: 357-370, 2009.

46 Parr C, Davies G, Nakamura T, Matsumoto K, Mason MD and Jiang WG: The HGF/SF-induced phosphorylation of paxillin, matrix adhesion and invasion of prostate cancer cells were suppressed by NK4, an HGF/SF variant. Biochem Biophys Res Commun 285: 1330-1337, 2001.

47 Martin TA, Parr C, Davies G, Watkins G, Lane J, Matsumoto K, Nakamura T, Mansel RE and Jiang WG: Growth and angiogenesis of human breast cancer in a nude mouse tumour model is reduced by NK4, a HGF/SF antagonist. Carcinogenesis 24: 1317-1323, 2003.

48 Van Slambrouck S, Jenkins AR, Romero AE and Steelant WF: Reorganization of the integrin alpha2 subunit controls cell adhesion and cancer cell invasion in prostate cancer. Int $\mathrm{J}$ Oncol 34: 1717-1726, 2009.
Received April 6, 2017

Revised April 20, 2017

Accepted April 24, 2017 